\title{
Modeling and Control of Standalone PMSG WECS for Grid Compatibility at Varying Wind Speeds
}

\author{
Shilpa Mishra ${ }^{\# 1}$ S Chatterji ${ }^{\# 2}$ Shimi S.L. ${ }^{\# 3}$ Sandeep Shukla ${ }^{\# 4}$ \\ ${ }^{1}$ M.E. (Student Instrumentation and Control), NITTTR Chandigarh, India \\ ${ }^{2}$ Professor and Head, ${ }^{3}$ Assistant Professor, Dept. of Electrical Engineering, NITTTR Chandigarh, India \\ ${ }^{4}$ Phd Research Scholar EE, RGIPT, Raebareli India
}

\begin{abstract}
Wind energy is one of the most available and exploitable forms of renewable energy. Variable speed PMSG based Wind Energy Conversion System (WECS) offers many advantages compared to the fixed speed squirrel cage induction generators such as improved stator output operation at better power factor, no maintenance cost for gear box (as it is directdriven) reduction in weight and losses, higher efficiency and ability to run at low speeds. The elimination of the gear box and brushes can enhance the efficiency of wind turbine by $10 \%$. In this paper a Permanent Magnet Synchronous Generator (PMSG) is modeled whose stator is connected to the constant single phase load (in place of grid) through AC/DC thyristors based rectifier followed by capacitor (dc-link) and DC/DC converter control. Overall arrangement provides constant output to connected load if applied with proper controlling techniques. Hence this proposed wind generation system design can be extended for grid connection also via DC/AC inverter control. Results are simulated and verified in MATLAB/Simulink platform at constant rated $(12 \mathrm{~m} / \mathrm{s})$ and varying (stepped) wind speed for smooth and constant output voltage.
\end{abstract}

Keywords - WECS, Direct-Driven PMSG, Thyristor Converter control, dc-link voltage Introduction

\section{INTRODUCTION}

It is important to find an alternative form of energy before the world's fossil fuels are depleted as it is predicted that oil and gas reserves will be depleted by 2032[1]. Wind energy has been the subject of much recent research and development. The only negative point that degrades the performance of Wind Energy Conversion System (WECS) in terms of maximum utilization of available power is high variation in wind-velocity (ranging from $3 \mathrm{~m} / \mathrm{s}$ to $15 \mathrm{~m} / \mathrm{s}$ and above). Now a day's wind system operation is widely being worked out so as to extract maximum active power at all possible wind speeds with least detrimental effects on overall performance. In a fixed speed wind turbine system, the generator rotates at an almost constant speed for which it is designed regardless of variation in wind speed.

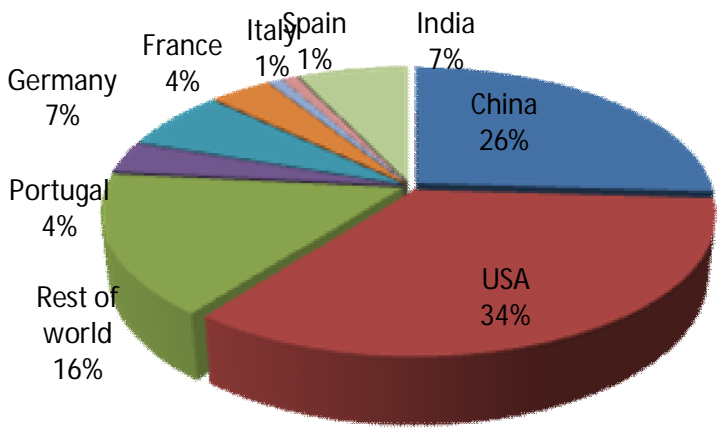

Fig.1 Contribution of Different Countries to Total Installed Wind Power Globally

As a result, the turbine will be the most efficient in extracting the maximum power from the wind for only one particular wind speed and wasted significant amount of energy [2]. Also as turbine is forced to operate at constant speed, it necessary for the turbine to be extremely robust to withstand a significant amount of mechanical stress due to the wind speed fluctuations On the other hand with variable speed wind turbine systems the rotor of the generator is allowed to rotate freely. Thus, it is possible to control the rotor speed by the means of power electronics to maintain the optimum tip speed ratio at all times under varying wind conditions. Several different configurations are researched and developed like fixed speed system with a Squirrel Cage Induction Generator (SCIG), variable speed system with Permanent Magnet Synchronous Generator (PMSG) and Doubly Fed Induction Generator (DFIG) to improve the efficiency While recent research has considered larger scale designs, the economics of large volumes of permanent magnet material has limited their practical application. But now a day's as cost of magnet has fallen down in global market significantly, PMSG WT has become most 
International Journal of Engineering Trends and Technology (IJETT) - Volume17 Number 10-Nov2014

preferred system for wind generation. The primary advantage of Permanent Magnet Synchronous Generators (PMSG) is that they do not require any external excitation current. A major cost benefit in using the PMSG is the fact that a thyristor bridge rectifier may be used at the generator terminals since no external excitation current is needed. Further, the elimination of the gear box and brushes can increase the efficiency of wind turbine by $10 \%[2]-[4]$. Hence wind turbines generators based on Permanent Magnet Synchronous Generators (PMSG) without gear box is more useful over electrically excited machines [3]-[4].

Main objective of this research is to model and control the standalone PMSG wind turbine connected to RL load at different wind velocities in such a way to give constant and smooth output at desired voltage to load. The simulation results show that given PMSG wind turbine design can be extended for grid connection. Output power and voltage of WECS gets effectively smoothed using proposed method.

Pitch angle control is also provided in proposed model of WECS for adjusting the power output of the wind turbine when wind speed is above rated speed

\section{MODELLING OF PMSG WIND TURBINE IN MATLAB/SIMULINK}

This section will present mathematical model of PMSG based on WECS. It consists of wind energy conversion, wind turbine, drive train, PMSG and converter as show in Fig. 2

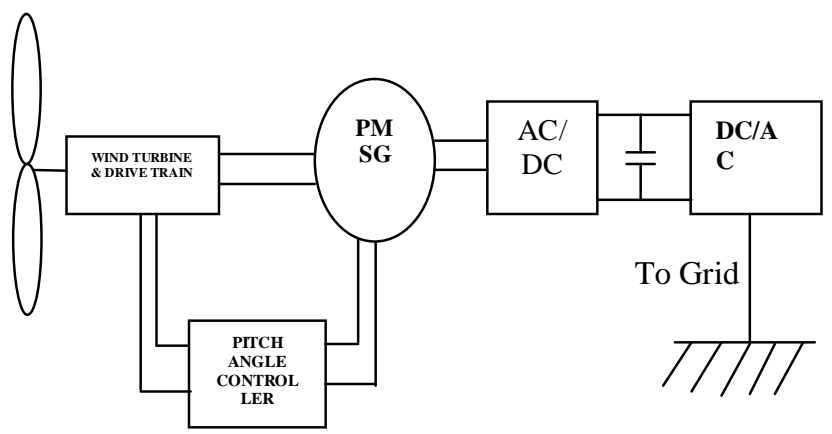

Fig.2 WECS Schematic Diagram Based on PMSG

A. Wind Turbine Aerodynamic Characteristic

$$
P_{\text {air }}=\frac{1}{2} \rho A v^{3}
$$

The aerodynamic efficiency of a wind turbine is described by the power coefficient function, $\mathrm{Cp}(\beta$, $\lambda$ ) given by,

$$
C_{p}=\frac{P_{m}}{P_{w}}
$$

Wind turbine is applied to convert the wind Energy to mechanical torque. The mechanical torque of turbine can be calculated from mechanical power at the turbine extracted from wind power. This fact of the wind speed after the turbine isn't zero. Then, the power coefficient of the turbine $(\mathrm{Cp})$ is used. The power coefficient is function of pitch angle $(\beta)$ and tip speed $(\lambda)$, pitch angle is angle of turbine blade whereas tip speed is the ratio of rotational speed and wind speed. The power coefficient maximum of $(\mathrm{Cp})$ is known as the limit of Betz. The power coefficient is given by [11],

$$
\frac{1}{\lambda_{i}}=\frac{1}{\lambda+0.08 \beta}-\frac{0.035}{\beta^{3}+1}
$$

The $C p-\lambda$ characteristics, for different values of the pitch angle $\beta$, are illustrated in Fig. 3. The power coefficient is given by,

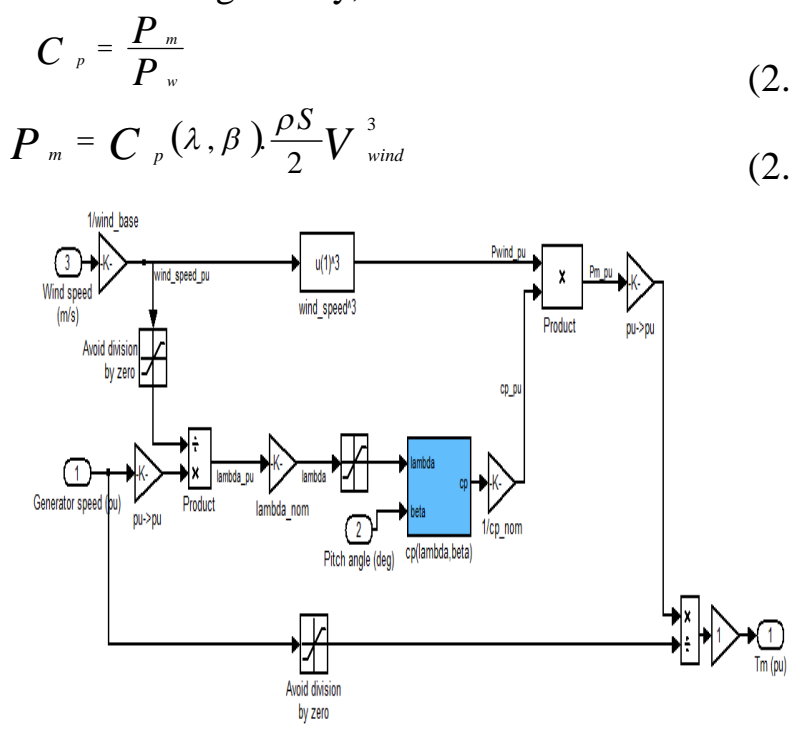

Fig.3 Wind Turbine MATLAB Model

The mechanical torque is given by,

$$
T_{m}=\frac{P_{m}}{\omega}
$$


International Journal of Engineering Trends and Technology (IJETT) - Volume17 Number 10-Nov2014

Where, $\mathrm{Cp}=$ Performance coefficient of the turbine, $\rho=$ Air density, $\mathrm{S}=$ Turbine swept are, Vwind $=$ Wind speed, $\lambda=$ Tip Speed Ratio, $\beta=$ Blade Pitch Angle.

\section{B. Modelling of PMSG}

The voltage equations of PMSG as shown in Fig. 5 are given by [12];

$\frac{d}{d t} i_{d}=\frac{1}{L_{d}} v_{d}-\frac{R}{L_{d}} i_{d}+\frac{L_{q}}{L_{d}} p \omega_{r} i_{q}$

$\frac{d}{d t} i_{q}=\frac{1}{L_{q}} v_{q}-\frac{R}{L_{q}} i_{q}+\frac{L_{d}}{L_{q}} p \omega_{r} i_{d}-\frac{\lambda \rho \omega_{r}}{L_{q}}$

The electromagnetic torque equation is given by

$T_{e}=0.75 \rho\left\lfloor\lambda_{i q}+\left(L_{d}-L_{q}\right) i_{d} i_{q}\right\rfloor$

Where, $\quad \mathrm{L}_{\mathrm{q}}=\mathrm{q}$ axis inductance, $\mathrm{L}_{\mathrm{d}}=\mathrm{d}$ Axisinductance, $\mathrm{R}=$ Resistance of the stator windings, $\mathrm{i}_{\mathrm{q}}$ $=\mathrm{q}$ axis current $\mathrm{id}=\mathrm{d}$ axis current, $\mathrm{v}_{\mathrm{q}}=\mathrm{q}$ axis voltage, $v_{d}=d$ axis voltage $\omega=$ Angular velocity of the rotor, $\lambda=$ Amplitude of flux induced, $\mathrm{p}=$ Number of pole pairs. The dynamic equations are given by,

$$
\begin{aligned}
& \frac{d \omega_{r}}{d t}=\frac{1}{J}\left(T_{e}-F \omega_{r}-T_{m}\right) \\
& \frac{d \theta}{d t}=\omega_{r}
\end{aligned}
$$

Where, $\quad \mathrm{J}=$ Inertia of rotor; $\mathrm{F}=$ Friction of rotor; $\theta$ $=$ Rotor angle.

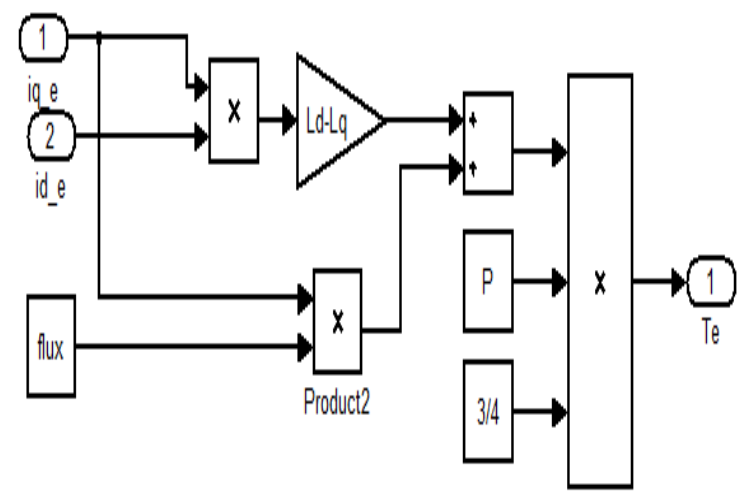

(i)

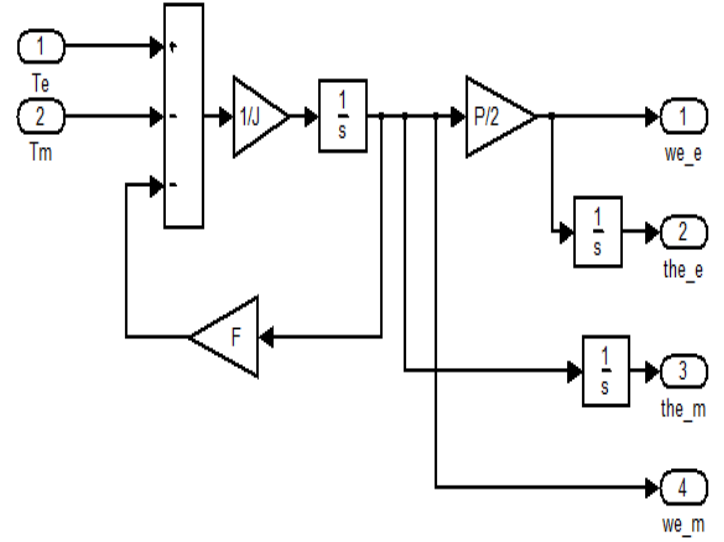

(ii)

Fig.5 Modelling of PMSG using Mathematical Equations for (i) Electromagnetic Torque (ii) Rotor Speed and Rotor Angle.

\section{Mathematical Inverse Park and Clark Transform}

A practical generator produces 3 phase AC power. For this reason, the inverse Park and Clarke transforms are introduced to implement the 3 phase AC output from the generator model. As Fig 6 shows, the transform from the stator axis reference frame $(\alpha, \beta)$ to the rotating reference frame $(d-q)$ is called the Park transform (Texas Instruments 1997). The Clarke transform is the transformation of the 3phase reference frame to the 2- phase orthogonal stator axis $(\alpha \beta)[12]$.

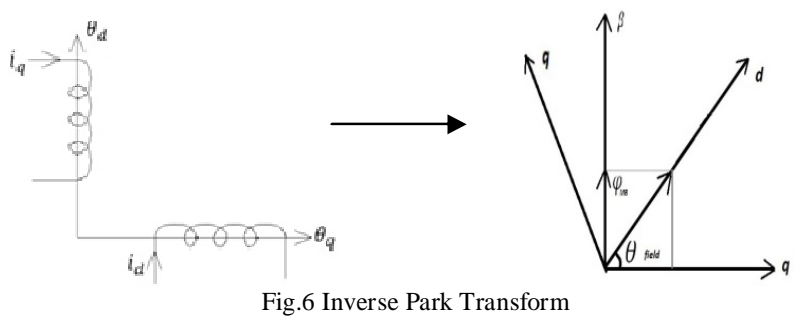

As of Fig. 6 illustration, assumes the $\alpha \beta$ frame has an angle $\theta$ Field with the $\mathrm{dq}$ frame, the inverse Park transform ( $\mathrm{dq}-\alpha \beta)$ which can be expressed as follows:

$$
\left[\begin{array}{l}
\alpha \\
\beta
\end{array}\right]=\left[\begin{array}{cc}
\cos \theta_{\text {field }} & -\sin \theta_{\text {field }} \\
\sin \theta_{\text {field }} & \sin \theta_{\text {field }}
\end{array}\right]\left[\begin{array}{l}
d \\
q
\end{array}\right]
$$

The mathematical inverse Clarke transform is given as follows; 


$$
\left[\begin{array}{l}
V_{a} \\
V_{b} \\
V_{c}
\end{array}\right]=\left[\begin{array}{cc}
1 & 0 \\
\frac{-1}{2} & \frac{\sqrt{3}}{2} \\
\frac{-1}{2} & \frac{\sqrt{-3}}{2}
\end{array}\right]\left[\begin{array}{l}
\alpha \\
\beta
\end{array}\right]
$$

\section{CONTROLLING OF PMSG WIND TURBINE}

PMSG wind turbine is provided with Power Electronic Control whether connected to grid, or operated for battery charging through load. The wind resource is intermittent, which results in the unstable PMSG output. However, in order for the system to reliably connect to the power grid or to the load for battery charging purpose, the dc bus link is required to be stable at constant voltage. Based on these requirements, the ac/dc rectifier control described in this section. The amplitude and frequency of the voltage output from a PMSG vary for a variable speed wind turbine when the wind speed changes from time to time, while in this circumstance the generator power output should be stabilized. The ac/dc converter circuits can be classified as uncontrolled rectifier and controlled rectifier circuits [9]-[10].

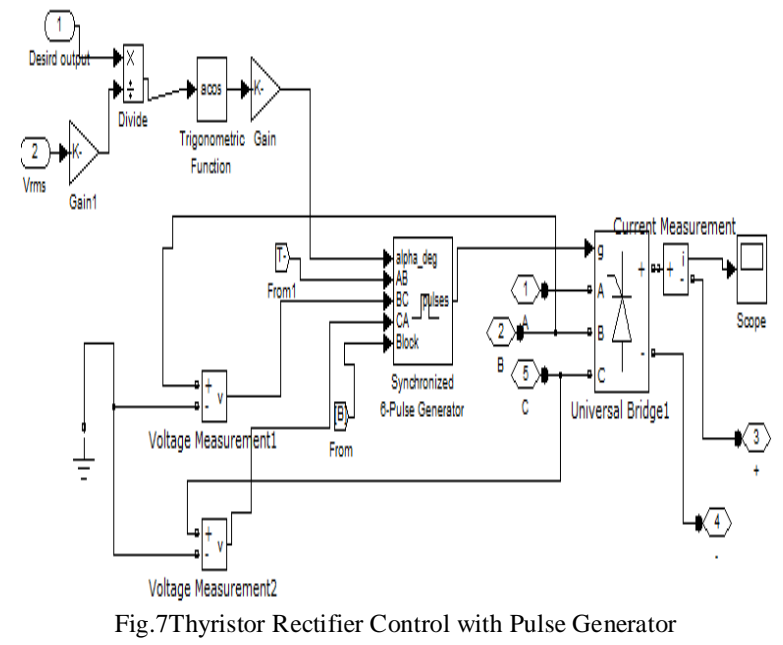

From Fig.7, when the wind turbine rotor speed wr1 is lower than the rated rotor speed of wind turbine, the error signal is negative and pitch angle is kept at its optimum value. When the rotor speed exceeds the rated (here for twice the rated rotor speed controller actuates), the error signal is positive and the pitch angle changes to a new value, at a finite rate, thereby reducing [the effective area of the blade resulting in the reduced power output. The PI controller inputs are in per-unit.

The most common typical rectifier topologies employed in variable speed PMSG wind turbine thyristor bridge rectifier control, At the generator side, the rectifier circuit consists of 6 passive thyristors. For this type of converter, the current from the wind turbine generator can only flow toward to the load, i.e. one way power flows from the generator to the load/grid[10].

The VSC controller stabilizes the voltage of the dc link using the capacitors between the thyristor based bridge rectifier and the constant RL load (considered here).

\section{Pitch Angle Power Control}

Pitch angle controller controls the wind flow around the wind turbine blade, thereby controlling the toque exerted on the turbine shaft. If the wind speed is less than the rated wind speed of the wind turbine, the pitch angle is kept constant at its optimum value.

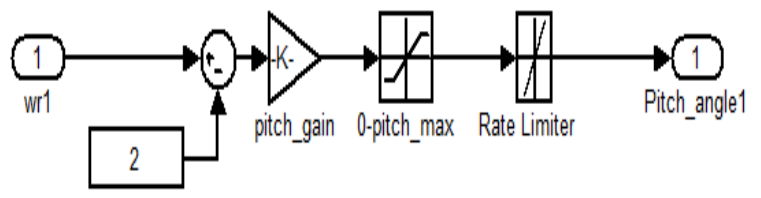

Fig.8 Pitch Angle Control Model in MATLAB with PI Control

From Fig.8, when the wind turbine rotor speed wr1 is lower than the rated rotor speed of wind turbine, the error signal is negative and pitch angle is kept at its optimum value. When the rotor speed exceeds the rated (here for twice the rated rotor speed controller actuates), the error signal is positive and the pitch angle changes to a new value, at a finite rate, thereby reducing [the effective area of the blade resulting in the reduced power output. The PI controller inputs are in per-unit.

The curve between the pitch angle and the wind speed for optimum power output is shown in Fig.9. 


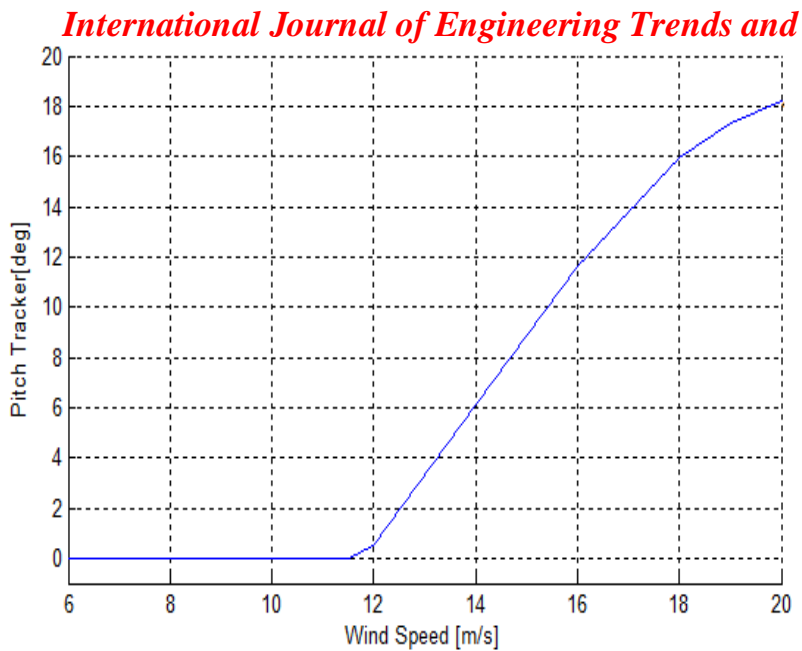

Fig. 8 Pitch Angle Variation with Wind Speeds

\section{SIMULATION MODEL}

Fig. 9 illustrates the simulation model of the PMSG wind turbine generator connected to constant RL load created in MATLAB/Simulink, under the condition of rated wind speed and rated rotational speed.

It consists of wind speed, wind turbine, drive train, PMSG, Pitch angle controller, rectifier, dc link capacitor and constant RL load. Fig.8 PMSG WT Simulation Model connected to RL load showing pitch control and power electronic Converter Control. At the generator side, the rectifier circuit consists of 6 passive thyristors. For this type of converter, the current from the wind turbine generator can only flow towards the load, i.e. one way power flows from the generator to the load/grid [10].

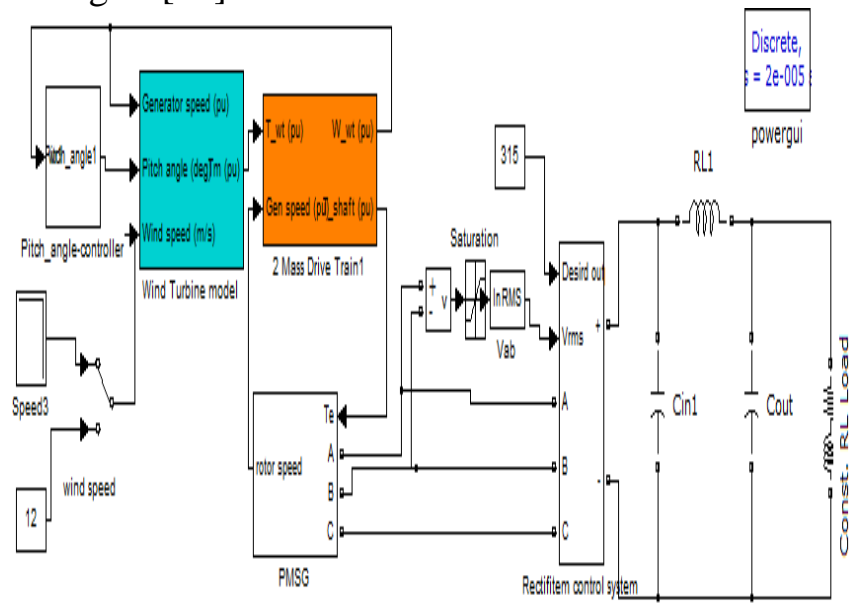

Fig. 9 PMSG Based WECS Simulation Model in MATLAB

Proposed simulation model has PMSG wind turbine with rated capacity of $8.5 \mathrm{KW}$. Output of wind turbine is connected to RL load via thyristor rectifier, IGBT boost converter circuit and dc link capacitor designed such that it would give constant output voltage across load at 325 Volts. Proposed model is simulated for constant wind speed input of $12 \mathrm{~m} / \mathrm{s}$ which is rated wind speed for wind turbine system under consideration.

Simulation results obtained thus give the performance of proposed PMSG based wind generation system load with RL by analyzing the dc link output voltage across load. Here objective is to achieve constant dc link output voltage at 315 volts (desired) and better power smoothing with least fluctuations across load IN such a way that it would be flexible to extend the design for grid connected PMSG wind generation system having constant voltage and frequency.

CASE 1- At wind speed $=12 \mathrm{~m} / \mathrm{s}$ (rated) as shown in Fig 10 below;

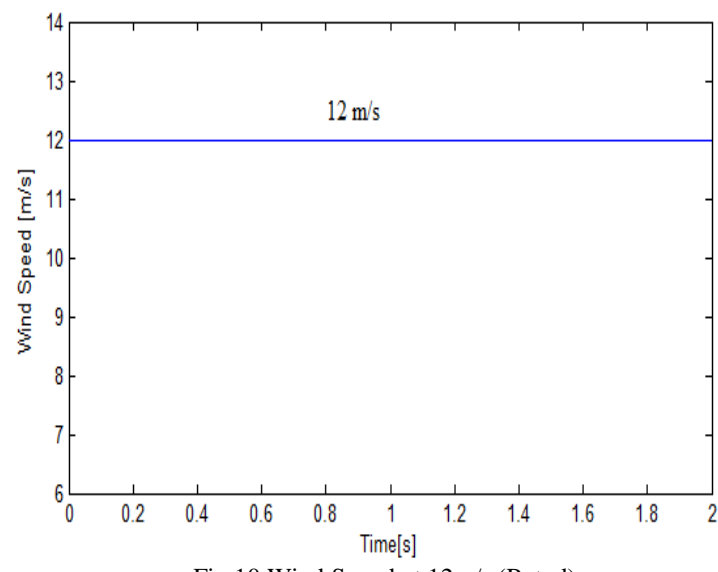

Fig.10 Wind Speed at $12 \mathrm{~m} / \mathrm{s}$ (Rated)

Here simulation results are shown for output voltage across load with proposed model. 


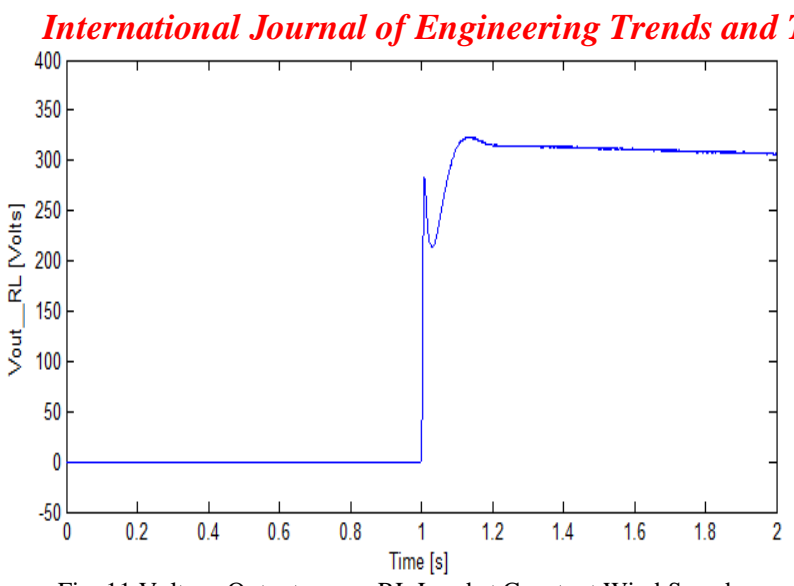

Fig. 11 Voltage Output across RL Load at Constant Wind Speed

It is observed from above results, that magnitude of voltage output is constant at 310 volts with almost no fluctuations.

CASE 2 - At varying wind speed (multistepped signal wave) as shown below from $12 \mathrm{~m} / \mathrm{s}$ to $7 \mathrm{~m} / \mathrm{s}$.

Due to change in wind speed from $12 \mathrm{~m} / \mathrm{s}$ to $7 \mathrm{~m} / \mathrm{s}$ suddenly (step-change) voltage output across RL load changes from 315 volts to around 300 volts suddenly at 3 second and then stabilizes at around 300 volts.
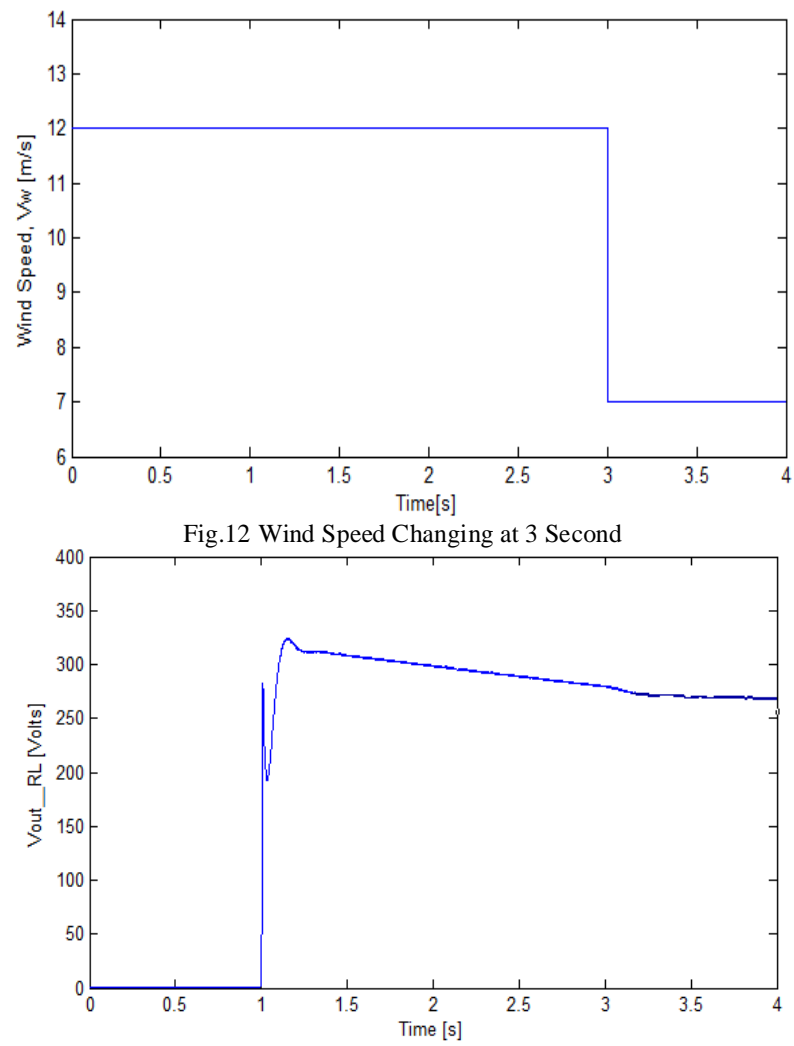

Fig. 11 Output Voltage across RL Load at Varying Wind Speed $y$ (IJETT) - Volume17 Number 10-Nov2014

VI. SIMULATION DATA

PMSG wind generator power rating is $8.5 \mathrm{KW}$.

Table 1. Showing Simulation Data

\begin{tabular}{|c|c|}
\hline $\begin{array}{c}\text { Stator direct axis } \\
\text { Inductance (Ld) }\end{array}$ & $0.0082 \mathrm{Mh}$ \\
\hline $\begin{array}{c}\text { Stator quadrature } \\
\text { axis Inductance (Lq) }\end{array}$ & $0.0082 \mathrm{mH}$ \\
\hline C_dc_link & 0.2 microfarad \\
\hline C_out & 1 microfarad \\
\hline Load resistance, R & 10 ohm \\
\hline $\begin{array}{c}\text { Load Inductance, L } \\
\text { Maximum output } \\
\text { power power }\end{array}$ & 0.8 pu of Rated \\
\hline
\end{tabular}

\section{CONCLUSION}

This paper shows the performance of variable speed PMSG based wind turbine when wind energy system is connected to RL load via dc link capacitor and thyristor converter control. For constant as well as changing wind speed it maintains the setting voltage to almost constant at $310 \mathrm{~V}$, which is very near to desired voltage across RL load. Also output is smooth having least amount of fluctuations which is highly needed for grid compatibility. Hence this arrangement provides wind turbine generator control and the DC bus voltage stabilization. It is thus proved that the proposed PMSG wind turbine design can be extended for constant grid connection.

\section{References}

[1] S.M. Muyeen,Junji Tamura Toshiaki Murata"Stability Augmentation of Grid-connected Wind Farm” Book, Springer-USA, October, 2009.

[2] Malcom Barnes, "Practical Variable Speed Drives and Power Electronics", Book, Newness Press, Elsevier, Oxford, Burlington, June 2003.

[3] Boldea I, "Variable Speed Generators", Handbook, Taylor and Francis Group LLC, 2006.

[4] Ackermann Thomas, "Wind Power in Power Systems, 2nd Edition", Book, John Wiley and Sons, England, 2012.

[5] O. Carlson, J. Hylander, and K. Thorborg, "Survey of Variable Speed Operation of Wind Turbines", European Union Wind Energy Conference, Goeteborg, Sweden, May 1996.

[6] D. Grenier, L. A. Dessaint, Y. Bonnassieux, and B. Lepiufle, "Experimental Nonlinear Torque Control of a Permanent Magnet 
International Journal of Engineering Trends and Technology (IJETT) - Volume17 Number 10-Nov2014 Synchronous Motor Using Saliency", IEEE Transactions on Industrial Electronics, Vol. 44, pp.680-687. No. 5, October 1997.

[7] . Mei and B. Pal, "Modal Analysis of Grid-Connected Doubly Fed Induction Generators," IEEE Transaction Energy Conversion, Vol. 22, No. 3, pp.728-736, Sep. 2007.

[8] R. Pena, J.C. Clare, G.M. Asher, "Doubly Fed Induction Generator Using Back-To-Back PWM Converters And Its Application to VariableSpeed Wind-Energy Generation," IEEE Proceeding Electrical Power Applications, Vol. 143, No. 3, May 1996.

[9] S. M. Muyeen, Rion Takahashi, Toshiaki Murata and Junji Tamura, "A Variable Speed Wind Turbine Control Strategy to Meet Wind Farm Grid Code Requirements", IEEE Transactions on Power Systems, Vol. 25, Issue 1, pp. 331 - 340, February 2010.

[10] Miller, E. Muljadi, and D. S. Zinger, "A Variable Speed Wind Turbine Power Control,” IEEE Trans. Energy Conversion, vol. 12, pp. 181-187,June 1997.

[11] Ekanayake, J.B, Holdsworth, L, Wu, X., Jenkins, N. "Dynamic Modelling of Doubly Fed Induction Generator Wind Turbines", IEEE Transaction on Power Systems, Vol. 18, No.2, pp. 803-809, 2003.

[12] H. Polinder, F. F. Avan der Pijl and P. Tavner, "Comparison of DirectDrive and Geared Generator Concepts for Wind Turbines", IEEE Transaction Energy Conversion, Vol. 21, Issue 3, pp. 543-550, September 2006. 